\title{
From simple to complex crystal chemistry in the $R E-A u-T t$ systems $(R E=$ La, Ce, Pr, Nd, Ho; Tt = Ge, Sn, Pb)
}

Sogol Lotfi ${ }^{1}$, Roy Arrieta ${ }^{1}$, Gordon Peterson¹, Pablo Delgado ${ }^{1}$, Jakoah Brgoch ${ }^{1,2 *}$

${ }^{1}$ Department of Chemistry, University of Houston, Houston, Texas 77204, United States

${ }^{2}$ Texas Center for Superconductivity, Houston 77204, Texas, United States

\begin{abstract}
Polar intermetallics are an intriguing class of compounds with complex relationships between composition and structure that are not fully understood. This work reports a systematic study of the underexplored ternary composition space $R E-\mathrm{Au}-T t(R E=\mathrm{La}, \mathrm{Ce}, \mathrm{Pr}, \mathrm{Nd}$, Ho; $T t=\mathrm{Ge}, \mathrm{Sn}, \mathrm{Pb})$ to expand our knowledge of the intriguing chemistry and diversity achievable with these metallic constituents. These composition spaces are particularly interesting because of the potential to find Au-bearing, highly polar intermetallic compounds. The elements were first reacted through arc welding under an inert atmosphere followed by annealing at $850^{\circ} \mathrm{C}$. X-ray diffraction of the products identified unreported eight compounds ranging from the simple $\mathrm{NaTl}$-type compounds $\mathrm{La}_{1.5} \mathrm{Au}_{2} \mathrm{~Pb}_{0.5}$, $\mathrm{Nd}_{2-x} \mathrm{Au}_{2} \mathrm{~Pb}_{x}$, and $\mathrm{Ho}_{2-x} \mathrm{Au}_{2} \mathrm{Sn}_{x}$, to the more structurally complex $\mathrm{La}_{5} \mathrm{AuPb}_{3}$ in the $\mathrm{Hf}_{5} \mathrm{CuSn}_{3}$-type structure and $\mathrm{Pu}_{3} \mathrm{Pd}_{4}$-type $R E_{3} \mathrm{Au}_{3} \mathrm{Ge}(R E=\mathrm{La}, \mathrm{Ce}, \mathrm{Pr}, \mathrm{Nd})$. First-principles electronic structure calculations revealed that a combination of Fermi surface-Brillouin zone interactions, electrostatic interactions, and delocalized metallic bonding contributes to the formation of these phases. These calculations show that a mixture of electrostatic and metallic bonding plays a dominant role in these phases. The RE-Au-Tt composition space remains full of potential for discovering materials with relevant magnetic and quantum properties, provided the crystal chemistry can be comprehended.
\end{abstract}




\section{Introduction}

Polar intermetallic compounds, a subset of metal-rich solids, have received much interest in academic laboratories and industrial research settings due to their complex crystal chemistry and potential for fascinating physical properties. Strictly defined, polar intermetallics are compounds that have a ratio of valence electrons per atom between $1.2 \leq(\mathrm{e} / \mathrm{a}) \leq 4$, existing between the limits of Hume-Rothery and Zintl phases, which contain $1 \leq(\mathrm{e} / \mathrm{a}) \leq 2$ and $(\mathrm{e} / \mathrm{a}) \geq 4$, respectively.1-4 Varying the e/a ratio and chemical composition provides a diversity of crystal structures and distinct chemical bonding motifs ranging from networks to clusters and quasicrystals..$^{5-7}$ The complexity of polar intermetallics can be justified because they contain structural and bonding features from both Hume-Rothery and Zintl type compounds. Unlike Hume-Rothery and Zintl phases, polar intermetallics suffer from complicated electron counting rules and the inability to assign definitive oxidation states, making predictions of crystal chemistry challenging. ${ }^{8}$ This is further convoluted by the wide range of compositions and stoichiometries that can be combined to form polar intermetallics, leaving large swathes of phase space unexplored. Therefore, to further our understanding, we must find new compounds that can help us unravel the intricacies of polar intermetallics, understand their structural tendencies, and further interpret their chemical bonding and overall crystal chemistry.

Ternary rare-earth $(R E)$ noble metal $(M)$ tetrels $(T t)$ are an exciting composition space to conduct such a study due to the relatively large electronegativity differences between the constituent elements. These phases can be quickly synthesized by arc-melting followed by annealing at accessible temperatures. ${ }^{9}$ The products crystallize easily, and numerous ternary compounds have been identified and characterized. Indeed, these compounds are of great interest owing to their fascinating structural chemistries and physical properties, including superconductivity (e.g., $R E_{2} \mathrm{Pt}_{3} \mathrm{Ge}_{5}$, $R E_{2} \mathrm{Ir}_{3} \mathrm{Ge}_{5}$ ), ${ }^{10}$ magnetocaloric effects (e.g., $\mathrm{GdRu}_{2} \mathrm{Ge}_{2}, R E_{2} M_{2} \mathrm{Sn}$ ), ${ }^{11,12}$ complex magnetic ordering (e.g., $R E \mathrm{CrGe}_{3}, \mathrm{Nd}_{117} \mathrm{Co}_{54} \mathrm{Sn}_{111}, R E_{2} \mathrm{Ni}_{2} \mathrm{~Pb}$ ), ${ }^{13,14}$ and other quantum phenomena (e.g., $\left.R E_{n+1} M_{n} T t_{3 n+1}\right) .{ }^{15}$ The 
magnetic properties stem from the interaction between the localized $4 f$ electrons of a rare-earth atom and the $d$ electrons of transition metal. ${ }^{16}$ However, there are no apparent mechanisms for controlling magnetism in these polar intermetallic compounds, even though some systems like $R E$-Ni-Ge have been exhaustively studied.17-19

It is possible to add further complexity to the crystal chemistry of polar intermetallics by studying gold-containing compounds. Au has the highest electronegativity of the noble metals, indicating that the most polarized intermetallics may exist in $M=\mathrm{Au}$ compositional spaces. However, many $R E-\mathrm{Au}-T t$ ternary phase spaces remain underexplored, with most systems reporting only one or two compounds. One common thread is the REAuTt phase, which crystallizes in rhombohedral LiGaGe structure type with space group $P 6_{3} m c$ (No. 186).20-22 The $[\mathrm{AuGe}]^{\mathrm{n}-}$ anionic sublattice in this compound features a strong polar-covalent bond between $\mathrm{Ge}-\mathrm{Au}$ and $\mathrm{Au}-\mathrm{Au}$, generating a threedimensional polyanionic backbone. $R E \mathrm{Au}_{2} \mathrm{Ge}_{2}$ phases in the tetragonal $\mathrm{ThCr}_{2} \mathrm{Si}_{2}$ structure type have also been identified in some $R E$ systems like $\mathrm{Ce}$ and $\mathrm{Pr}$, and are reported to order antiferromagnetically with Néel temperatures of 16 K and 11.9 K, respectively. ${ }^{19,23,24}$ More complex and unique topologies also pervade these systems, such as the orthorhombic $\mathrm{Ce}_{3} \mathrm{Pd}_{6} \mathrm{Sb}_{5}$ type formed in the $R E$-Au-Sn systems $(R E=\mathrm{Ce}, \mathrm{Nd}, \mathrm{Sm}) \cdot{ }^{25}$

This work identifies eight new compounds in the RE-Au-Tt (RE = La, Ce, Pr, Nd; Tt = Ge, Sn, $\mathrm{Pb}$ ternary phase space through a systematic study of these composition spaces at $850^{\circ} \mathrm{C}$. These compounds adopt three structure types spanning simple to complex crystal chemistry across the $\mathrm{Au}$ rich to $\mathrm{Au}$-poor composition range. They include $R E_{2-\mathrm{x}} \mathrm{Au}_{2} \mathrm{~Pb}_{x}(R E=\mathrm{La}, \mathrm{Nd})$ and $\mathrm{HoAu}_{2} \mathrm{Sn}$ in the NaTltype, $\mathrm{La}_{5} \mathrm{AuPb}_{3}$ in the $\mathrm{Hf}_{5} \mathrm{CuSn}_{3}$ type, and $R E_{3} \mathrm{Au}_{3} \mathrm{Ge}$ with $R E=\mathrm{La}, \mathrm{Ce}, \mathrm{Pr}, \mathrm{Nd}$ in the $\mathrm{Pu}_{3} \mathrm{Pd}_{4}$ structure type. Density functional theory (DFT) calculations were performed to interpret the origin of structural favorability for these phases and examine the nature of the covalent, ionic, and metallic 
contributions to polar intermetallic bonding. The results of this work will further our fundamental understanding of these systems and gold-containing polar intermetallic phases in general.

\section{Experimental}

Synthesis. The starting metals - gold (splatter, 99.999\%, Materion Advanced Chemical), tetrels Ge (powder, 99.99\%, Alfa Aesar), Sn (powder, 99.5\%, Alfa Aesar), and Pb (shot, W. H. Curtin \& Co.), and the rare-earth elements La, Ce, Pr, Nd, and Ho (filings, 99.8\%, HEFA Rare Earth), were weighed out in the desired stoichiometric ratios and ground together with an agate mortar and pestle to form a uniform sample with a total weight of $200 \mathrm{mg}$. The samples were cold-pressed into $6 \mathrm{~mm}$ pellets using a maximum pressure of 2500 psi and reacted under argon gas in a Centorr 5SA arc furnace with a current of 30-45 A. All samples were flipped and melted multiple times to ensure homogeneity. The weight loss for each sample after arc-melting was less than 2\%. Each resulting ingot was subsequently sealed in an evacuated fused silica tube (less than $4 \times 10^{-2}$ torr) and annealed in a Thermo Scientific Lindberg Blue M muffle furnace at $850^{\circ} \mathrm{C}$ for $200 \mathrm{~h}$, then cooled back to room temperature over 24 hours. The final products had a silvery metallic luster and were all brittle. The La-containing products showed some sensitivity to air fading to a dull black color over several days to weeks when left at ambient conditions. As a result, all products were stored in an argon atmosphere glove box $\left(\mathrm{O}_{2}<0.1 \mathrm{ppm} ; \mathrm{H}_{2} \mathrm{O}<0.1 \mathrm{ppm}\right)$. The preparation of $\mathrm{LaAuGe}_{3}, \mathrm{LaAuGe}_{2}$, $\mathrm{La}_{4} \mathrm{Au}_{5} \mathrm{Ge}_{11}, \mathrm{LaAu}_{2} \mathrm{Ge}, \mathrm{LaAu}_{3} \mathrm{Ge}, \mathrm{La}_{2} \mathrm{AuGe}$, and $\mathrm{La}_{2} \mathrm{Au}_{2} \mathrm{Ge}$ was also attempted following the same synthetic procedure; however, the products from these reactions were all multiphase based on powder X-ray diffraction and fully indexed to known compounds.

Powder X-ray diffraction. X-ray powder diffractograms were collected at room temperature using a PANalytical X'Pert powder diffractometer equipped with $\mathrm{Cu}$ K $\alpha$ radiation $(\lambda=1.54183 \AA$ ). The samples were prepared by grinding the annealed ingots in the glovebox using an agate mortar and 
pestle. The fine powder was then spread on a zero-diffraction silicon plate and measured from $5^{\circ}$ to $90^{\circ} 2 \theta$. Le Bail refinements were carried out on the collected data of all compositions to confirm phase purity and determine the lattice parameters using the EXPGUI interface for the General Structure Analysis System (GSAS).26, 27 Refined unit cell parameters for all synthesized compounds are given in Table 1, and Le Bail refinement of powder X-ray diffraction data is shown in Figure S1. A shifted-Chebyshev function was used to model the background. All crystal structures were visualized using VESTA ${ }^{28}$ and Diamond $3 .{ }^{29}$

Table 1. Refined unit cell parameters for all compounds from powder X-ray diffraction.

\begin{tabular}{lllllll}
\hline & $a(\AA)$ & $b(\AA)$ & $c(\AA)$ & $\alpha\left(^{\circ}\right)$ & $\beta\left(^{\circ}\right)$ & $\gamma\left({ }^{\circ}\right)$ \\
\hline $\mathrm{La}_{3} \mathrm{Au}_{3} \mathrm{Ge}$ & $14.0300(4)$ & $14.0300(4)$ & $6.2015(6)$ & 90 & 90 & 120 \\
$\mathrm{Ce}_{3} \mathrm{Au}_{3} \mathrm{Ge}$ & $13.865(2)$ & $13.865(2)$ & $6.150(1)$ & 90 & 90 & 120 \\
$\mathrm{Pr}_{3} \mathrm{Au}_{3} \mathrm{Ge}$ & $13.8118(5)$ & $13.8118(5)$ & $6.1249(5)$ & 90 & 90 & 120 \\
$\mathrm{Nd}_{3} \mathrm{Au}_{3} \mathrm{Ge}$ & $13.7075(4)$ & $13.7075(4)$ & $6.0935(5)$ & 90 & 90 & 120 \\
$\mathrm{La}_{5} \mathrm{AuPb}_{3}$ & $9.692(1)$ & $9.692(1)$ & $7.0087(9)$ & 90 & 90 & 120 \\
$\mathrm{La}_{1.5} \mathrm{Au}_{2} \mathrm{~Pb}_{0.5}$ & $7.2252(1)$ & $7.2252(1)$ & $7.2252(1)$ & 90 & 90 & 90 \\
$\mathrm{Nd}_{2-x} \mathrm{Au}_{2} \mathrm{~Pb}_{x}$ & $7.0906(6)$ & $7.0906(6)$ & $7.0906(6)$ & 90 & 90 & 90 \\
$\mathrm{Ho}_{2-x} \mathrm{Au}_{2} \mathrm{Sn}_{x}$ & $6.86690(4)$ & $6.86690(4)$ & $6.86690(4)$ & 90 & 90 & 90 \\
\hline
\end{tabular}

Single-crystal X-ray diffraction. Single crystals were harvested from crushed samples of the Lacontaining phases and mounted on the end of pulled glass fibers. Crystals were silvery grey and lustrous and generally formed as small cubes or plates approximately 10-50 $\mu \mathrm{m}$ in size. Diffraction data sets were collected as omega scans $\left(0.5^{\circ}\right.$ scan width at $60 \mu \mathrm{m}$ detector distance $)$ on a Bruker Apex II platform diffractometer equipped with a 4KCCD Apex II detector and Mo K $\alpha$ radiation source at 296 K. Peak hunting, indexing, data integration, and finalization were performed with the provided Bruker APEX II software. The structures of each crystal were solved using the shelXle program package for SHELX refined on $F_{o}{ }^{2} \cdot{ }^{30}$ Anisotropic atomic displacement parameters for each structural solution are given in Table S1. Solved structures have been submitted to the CCDC and can be 
obtained under deposition numbers 2129946-2129948. Crystal structures were visualized with the Crystal Impact Diamond 3 and VESTA software packages. ${ }^{28,29}$

Table 2. Crystallographic data for the nominally loaded $\mathrm{La}_{1.5} \mathrm{Au}_{2} \mathrm{~Pb}_{0.5}, \mathrm{La}_{5} \mathrm{AuPb}_{3}$, and $\mathrm{La}_{3} \mathrm{Au}_{3} \mathrm{Ge}$ from single-crystal X-ray diffraction

\begin{tabular}{|c|c|c|c|}
\hline Nominal formula & $\mathrm{La}_{1.5} \mathrm{Au}_{2} \mathrm{~Pb}$ & $\mathrm{La}_{5} \mathrm{AuPb}_{3}$ & $\mathrm{La}_{3} \mathrm{Au}_{3} \mathrm{Ge}$ \\
\hline Refined formula & $\mathrm{La}_{1.58(3)} \mathrm{Au}_{2} \mathrm{~Pb}_{0.42(3)}$ & $\mathrm{La}_{5} \mathrm{Au}_{0.91(1)} \mathrm{Pb}_{3}$ & $\mathrm{La}_{3} \mathrm{Au}_{3.17(1)} \mathrm{Ge}_{0.83(1)}$ \\
\hline Formula mass $\left(\mathrm{g} \mathrm{mol}^{-1}\right)$ & 700.37 & 1494.83 & 1101.55 \\
\hline Space group; $Z$ & $F d \overline{3} m ; 4$ & $\mathrm{PG}_{3} / \mathrm{mcm} ; 2$ & $R \overline{3} ; 6$ \\
\hline$a, b(\AA)$ & $7.2315(4)$ & $9.7121(3)$ & $14.04(1)$ \\
\hline$c(\AA)$ & $7.2315(4)$ & $7.0033(3)$ & $6.220(5)$ \\
\hline$V\left(\AA^{3}\right)$ & $378.17(6)$ & $572.08(4)$ & $1062(2)$ \\
\hline$\rho_{\text {calc }}\left(\mathrm{g} \mathrm{cm}^{-3}\right)$ & 12.3006 & 8.67731 & 6.88628 \\
\hline Absorption correction & \multicolumn{3}{|c|}{ Multi-scan } \\
\hline Radiation & \multicolumn{3}{|c|}{ 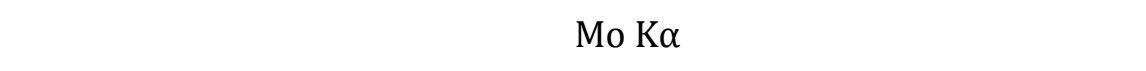 } \\
\hline$\mu\left(\mathrm{mm}^{-1}\right)$ & 113.162 & 73.701 & 83.445 \\
\hline$\theta$ range (deg.) & $4.88-34.225$ & $2.421-30.501$ & $2.901-27.563$ \\
\hline \multirow[t]{3}{*}{$h k l$ ranges } & $-10 \leq h \leq 9$ & $-13 \leq h \leq 13$ & $-18 \leq h \leq 17$ \\
\hline & $-11 \leq k \leq 10$ & $-11 \leq k \leq 13$ & $-13 \leq k \leq 18$ \\
\hline & $-11 \leq l \leq 9$ & $-10 \leq l \leq 9$ & $-8 \leq l \leq 7$ \\
\hline No. reflections; $R_{\text {int }}$ & $743 ; 0.0124$ & $6479 ; 0.0426$ & $1691 ; 0.055$ \\
\hline No. unique reflections & 51 & 343 & 539 \\
\hline No. parameters & 4 & 15 & 26 \\
\hline$R(F)$ for $F_{0}^{2}>2 \sigma\left(F_{0}^{2}\right)^{a}$ & 0.0270 & 0.0331 & 0.0439 \\
\hline$R_{\mathrm{w}}\left(F_{\mathrm{o}}^{2}\right)^{\mathrm{b}}$ & 0.0538 & 0.0791 & 0.1132 \\
\hline Goodness of fit & 1.230 & 1.081 & 1.056 \\
\hline$(\Delta \rho)_{\max },(\Delta \rho)_{\min }\left(\mathrm{e} \AA^{-3}\right)$ & $0.815,-1.969$ & $2.455,-1.983$ & $4.097,-2.838$ \\
\hline
\end{tabular}

Table 3. Refined atomic coordinates and equivalent isotropic displacement parameters for the nomrinally loaded compounds (a) $\mathrm{La}_{1.5} \mathrm{Au}_{2} \mathrm{~Pb}_{0.5}$, (b) $\mathrm{La}_{5} \mathrm{AuPb}_{3}$, and (c) $\mathrm{La}_{3} \mathrm{Au}_{3} \mathrm{Ge}$.
Compound
atom Wyck. Occ.
$Y$
$Z$
$U_{\text {eq }}\left(\AA^{2}\right)^{\text {a }}$

(a) $\mathrm{La}_{1.5} \mathrm{Au}_{2} \mathrm{~Pb}_{0.5}$ 


\begin{tabular}{|c|c|c|c|c|c|c|c|}
\hline & Au1 & $8 a$ & 1 & $1 / 8$ & $5 / 8$ & $5 / 8$ & $0.0212(4)$ \\
\hline & La1 & $8 d$ & $0.79(2)$ & $3 / 8$ & $7 / 8$ & $7 / 8$ & $0.0277(6)$ \\
\hline & $\mathrm{Pb} 1$ & $8 d$ & $0.21(2)$ & $3 / 8$ & $7 / 8$ & $7 / 8$ & $0.0277(6)$ \\
\hline \multicolumn{8}{|l|}{ (b) $\mathrm{La}_{5} \mathrm{AuPb}_{3}$} \\
\hline & $\mathrm{Pb} 1$ & $6 g$ & 1 & $0.6132(1)$ & 1 & $3 / 4$ & $0.0202(3)$ \\
\hline & Au1 & $2 b$ & $0.907(9)$ & 1 & 1 & $1 / 2$ & $0.0310(7)$ \\
\hline & La1 & $4 d$ & 1 & $1 / 3$ & $2 / 3$ & $1 / 2$ & $0.0192(3)$ \\
\hline & $\mathrm{La} 2$ & $6 g$ & 1 & 1 & $0.2619(2)$ & $3 / 4$ & $0.0213(4)$ \\
\hline \multicolumn{8}{|l|}{ (c) $\mathrm{La}_{3} \mathrm{Au}_{3} \mathrm{Ge}$} \\
\hline & $\mathrm{Au} 1$ & $18 f$ & $0.89(1)$ & $0.72301(7)$ & $0.94251(7)$ & $0.2178(1)$ & $0.0174(3)$ \\
\hline & $\mathrm{Ge} 1$ & $18 f$ & $0.11(1)$ & $0.72301(7)$ & $0.94251(7)$ & $0.2178(1)$ & $0.0174(3)$ \\
\hline & La1 & $18 f$ & 1 & $0.4988(1)$ & $0.8761(1)$ & $0.4019(2)$ & $0.0178(5)$ \\
\hline & $\mathrm{Au} 2$ & $3 a$ & $0.56(2)$ & $1 / 3$ & $2 / 3$ & $2 / 3$ & $0.037(1)$ \\
\hline & $\mathrm{Ge} 2$ & $3 a$ & $0.44(2)$ & $1 / 3$ & $2 / 3$ & $2 / 3$ & $0.037(1)$ \\
\hline & Au3 & $3 b$ & $0.43(2)$ & $1 / 3$ & $2 / 3$ & $1 / 6$ & $0.041(2)$ \\
\hline & Ge3 & $3 b$ & $0.57(2)$ & $1 / 3$ & $2 / 3$ & $1 / 6$ & $0.041(2)$ \\
\hline
\end{tabular}

a $U_{\text {eq }}$ is defined as one-third of the trace of the orthogonalized $U_{i j}$ tensor.

Table 4. Selected refined bond lengths $[\AA]$ for $\mathrm{La}_{1.5} \mathrm{Au}_{2} \mathrm{~Pb}_{0.5}, \mathrm{La}_{5} \mathrm{AuPb}_{3}$, and $\mathrm{La}_{3} \mathrm{Au}_{3} \mathrm{Ge}$ from single-crystal $\mathrm{X}$-ray diffraction.

\begin{tabular}{|c|c|c|c|c|c|}
\hline \multicolumn{2}{|c|}{$\mathrm{La}_{1.5} \mathrm{Au}_{2} \mathrm{~Pb}_{0.5}$} & \multicolumn{2}{|c|}{$\mathrm{La}_{5} \mathrm{AuPb}_{3}$} & \multicolumn{2}{|c|}{$\mathrm{La}_{3} \mathrm{Au}_{3} \mathrm{Ge}$} \\
\hline $\mathrm{Au} 1-\mathrm{Au} 1$ & $3.131(1)$ & Pb1 - La2 & $3.3206(7)$ & $\mathrm{Au} 1-\mathrm{Au} 1$ & $3.020(2)$ \\
\hline Au1-La1 & $3.131(1)$ & $\mathrm{Pb} 1-\mathrm{La} 2$ & $3.413(2)$ & Au1 - La1 & $3.026(2)$ \\
\hline Au1 - La1 & $3.6158(2)$ & $\mathrm{Pb} 1$ - La1 & $3.4825(7)$ & Au1 - La1 & $3.125(3)$ \\
\hline \multirow[t]{8}{*}{ La1 - La1 } & $3.1313(2)$ & $\mathrm{Pb} 1$ - La1 & $3.4844(7)$ & $\mathrm{Au} 1-\mathrm{Au} 1$ & $3.170(2)$ \\
\hline & & $\mathrm{Pb} 1-\mathrm{La} 2$ & $3.7061(6)$ & Au1 - La1 & $3.128(3)$ \\
\hline & & Au1 - La2 & $3.087(1)$ & Au1 - La1 & $3.231(3)$ \\
\hline & & La1 - La1 & $3.5016(2)$ & Au1 - La1 & $3.334(3)$ \\
\hline & & La1 - La2 & $3.5017(2)$ & Au1 - La1 & $3.385(3)$ \\
\hline & & La1 - La2 & $4.034(1)$ & Au1 - La1 & $3.455(2)$ \\
\hline & & La1 - La2 & $4.035(1)$ & La1 - Au3 & $3.059(2)$ \\
\hline & & & & $\mathrm{Au} 2-\mathrm{Au} 3$ & $3.110(2)$ \\
\hline
\end{tabular}


Electronic Structure Calculations. Density functional theory (DFT) calculations using the Vienna Abinitio Simulation Package (VASP) version 5.4.4 were performed to optimize the geometries with a convergence criterion of $1 \times 10^{-3} \mathrm{eV} / \AA$ and calculate the wave functions and charge densities of each reported compound with a convergence criterion of $1 \times 10^{-8} \mathrm{eV} \cdot{ }^{31,32}$ DFT optimized total energies, unit cell parameters, and atomic positions are listed in Tables S2-S5. Calculations were done using the projector augmented wave (PAW) potentials with exchange and correlation described by PerdewBurke-Ernzerhof (PBE) with a $\Gamma$-centered Monkhorst-Pack $k$-point grid containing at least $1000 k$ points atom ${ }^{-1} .33$, 34 Density of states (DOS) and crystal orbital Hamilton population (COHP) calculations were carried out using the Local-Orbital Basis Suite toward Electronic Structure (LOBSTER). ${ }^{35,36}$ Bader charges on each atomic position were determined using the Bader program for VASP. ${ }^{37-39}$

\section{Results and Discussion}

Synthesis and Structural Characterization. Seven ternary intermetallic systems containing a rare earth $(R E)$ metal, gold, and a main group tetrel metal $(T t)$ were synthetically explored: $\mathrm{La}-\mathrm{Au}-\mathrm{Pb}$, $\mathrm{Nd}-\mathrm{Au}-\mathrm{Pb}, \mathrm{Ho}-\mathrm{Au}-\mathrm{Sn}, \mathrm{La}-\mathrm{Au}-\mathrm{Ge}, \mathrm{Ce}-\mathrm{Au}-\mathrm{Ge}, \mathrm{Pr}-\mathrm{Au}-\mathrm{Ge}$, and Nd-Au-Ge. In each case, elements were mixed in stoichiometric ratios, arc welded under flowing Ar, and sealed in fused silica ampoules under vacuum and annealed at $850^{\circ} \mathrm{C}$ for $200 \mathrm{~h}$. Structural characterization using single-crystal and powder X-ray diffraction of the resulting products indicated the formation of eight previously unknown compounds in three distinct classes: A NaTl structure type for $R E_{2-x} A_{2} T t_{x}\left(\operatorname{La}_{1.5} A_{2} \mathrm{~Pb}_{0.5}\right.$, $\mathrm{Nd}_{2-x} \mathrm{Au}_{2} \mathrm{~Pb}_{x}, \mathrm{Ho}_{2-x} \mathrm{Au}_{2} \mathrm{Sn}_{x}$ ), followed by $\mathrm{La}_{5} \mathrm{AuPb}_{3}$ in the $\mathrm{Hf}_{5} \mathrm{CuSn}_{3}$ structure type, and the most complex $R E_{3} \mathrm{Au}_{3} \mathrm{Ge}\left(\mathrm{La}_{3} \mathrm{Au}_{3} \mathrm{Ge}, \mathrm{Ce}_{3} \mathrm{Au}_{3} \mathrm{Ge}, \mathrm{Pr}_{3} \mathrm{Au}_{3} \mathrm{Ge}, \mathrm{Nd}_{3} \mathrm{Au}_{3} \mathrm{Ge}\right)$ in the $\mathrm{Pu}_{3} \mathrm{Pd}_{4}$ structure type. 


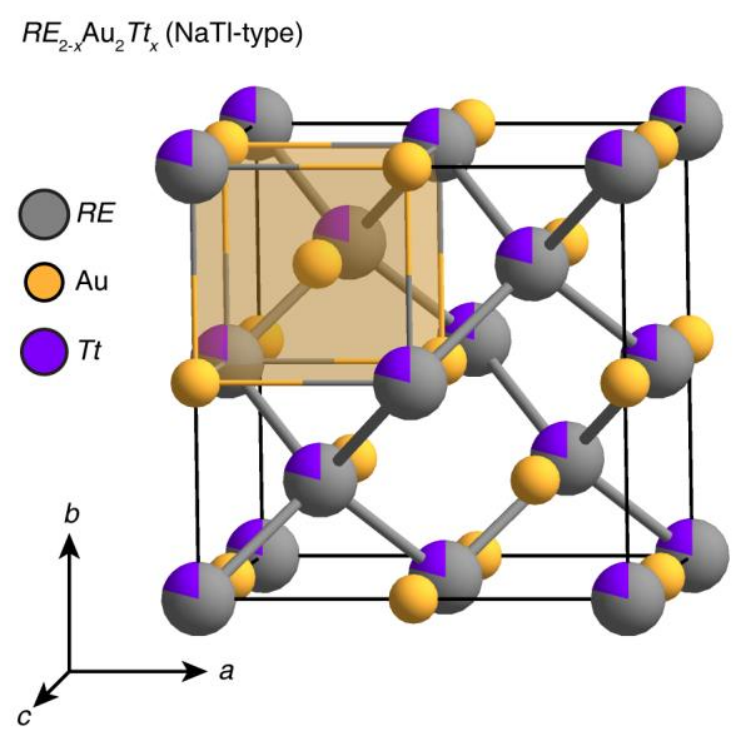

Figure 1. The structure of $R E_{2-x} \mathrm{Au}_{2} \mathrm{~Pb}_{x}$ in the cubic NaTl-type.

The first class of compounds presented in this work are three newly discovered $R E_{2-x} A_{u_{2}} T t_{x}(R E=\mathrm{La}$, $\mathrm{Nd}, \mathrm{Ho}, \mathrm{Tt}=\mathrm{Pb}, \mathrm{Sn}$ ) compounds adopting the NaTl structure type: $\mathrm{La}_{1.5} \mathrm{Au}_{2} \mathrm{~Pb}_{0.5}, \mathrm{Nd}_{2-\mathrm{x}} \mathrm{Au}_{2} \mathrm{~Pb}_{x}$, and $\mathrm{Ho}_{2}$ ${ }_{x} \mathrm{Au}_{2} \mathrm{Sn}_{x}$. These compounds, illustrated in Figure 1, form an ordered superstructure of the simple body-centered cubic arrangement, in which Au atoms alternate with statistically mixed $R E$ and $T t$ sites. The refined unit cell parameters of all three compounds were determined through Le Bail refinement of powder X-ray diffraction, and the fit diffractogram for the $\mathrm{La}_{1.5} \mathrm{Au}_{2} \mathrm{~Pb}_{0.5}$ phase is shown in Figure S1a (refined cell parameters for all structures given in Table 1). For the $\mathrm{La}-\mathrm{Au}-\mathrm{Pb}$ analog, the $R E / T t$ elemental mixing was determined through single-crystal X-ray diffraction to be $79(2) \% \mathrm{La}$

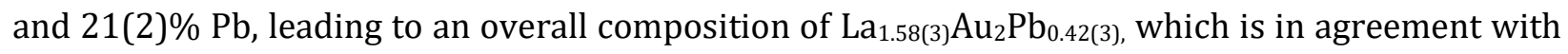
the nominally loaded $\mathrm{La}_{1.5} \mathrm{Au}_{2} \mathrm{~Pb}_{0.5}$ composition. Similar statistical mixing is expected for the $\mathrm{Nd}$ and Ho structures. Crystallographic and structural parameters for this structure solution are provided in Tables 2-4.

NaTl-type phases are classically considered Zintl compounds, and many examples of binary alkalimain group metal NaTl-type compounds are known. The ternary compositions related to this group of compounds containing $\mathrm{Au}$ are $\mathrm{Li}_{2} \mathrm{AuSb}, \mathrm{Li}_{2} \mathrm{Au}_{0.75} \mathrm{Si}_{1.25}$, and $\mathrm{Li}_{2} \mathrm{Au}_{0.25} \mathrm{In}_{1.75}$ systems, ${ }^{40}$ their 
conventional classification as Zintl compounds conforms with a calculation of valence electrons per atom. For example, the most electron-rich of these species, $\mathrm{Li}_{2} \mathrm{Au}$ lies just at the upper bound of the Zintl edge (2 e/a). The NaTl-type structure containing lanthanide atoms will form slightly above this limit, including $\mathrm{CeMg}_{3}$ and $\mathrm{Dy}_{0.67} \mathrm{Mg}_{1.33}$, but so far only when having the small and electropositive element Mg. ${ }^{41,42}$ By contrast, the $R E-A u-T t$ phases presented here significantly eclipse this threshold, with $\mathrm{La}_{1.5} \mathrm{Au}_{2} \mathrm{~Pb}_{0.5}$ forming at a valence density of $2.625 \mathrm{e} / \mathrm{a}$. This is indicative that these compounds represent a step into a previously unexplored compositional region of non-Zintl NaTl-type phases.

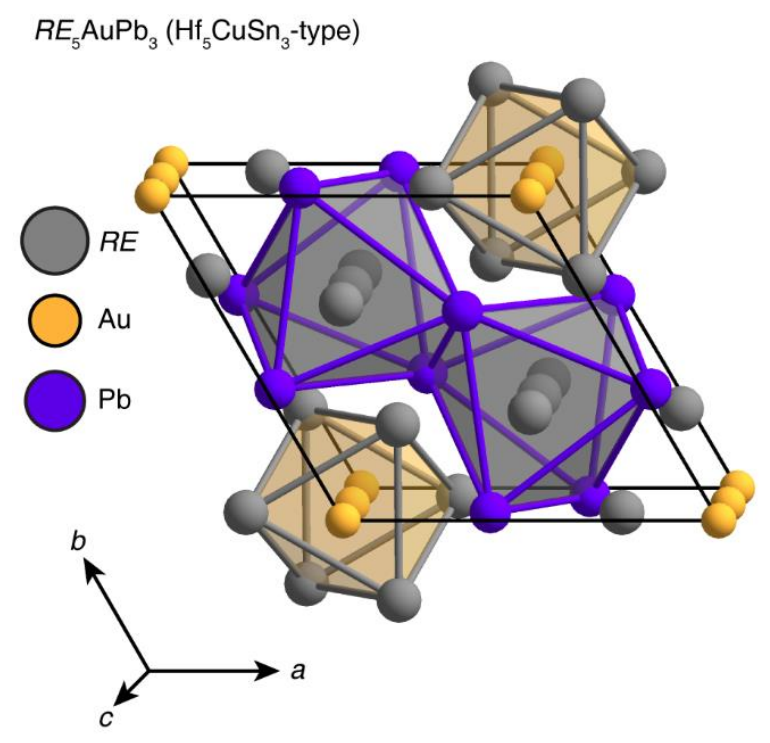

Figure 2. The structure of $\mathrm{Hf}_{5} \mathrm{CuSn}_{3}$-type $\mathrm{La}_{5} \mathrm{AuPb}_{3}$.

The next compound identified is $\mathrm{La}_{5} \mathrm{AuPb}_{3}$ forms in the rhombohedral $\mathrm{Hf}_{5} \mathrm{CuSn}_{3}$ structure type..$^{43}$ The structure of $\mathrm{La}_{5} \mathrm{AuPb}_{3}$ is shown in Figure 2, and refined unit cell parameters from Le Bail powder (Figure S1d) and single-crystal diffraction are given in Tables 1 and 2, respectively. This structure type is, in itself, a derivative of the classic $\mathrm{Mn}_{5} \mathrm{Si}_{3}$ structure, ${ }^{44}$ which consists of two crystallographically distinct columns of face-sharing octahedra that run along the $c$ axis. In the $\mathrm{Hf}_{5} \mathrm{CuSn}_{3}$-type, noble metal atoms stuff the usually empty $R E$ octahedra centered at the unit cell vertices, creating a one-dimensional chain of $91 \%$ occupied Au sites within a distance comparable to 
metallic bonding interactions. These $\mathrm{Au} @ \mathrm{La}_{6}$ octahedra are tiled in the $a b$ plane with $\mathrm{La} @ \mathrm{~Pb}_{6}$ octahedra, which share faces along the $c$ axis and edges the in $a b$-plane.

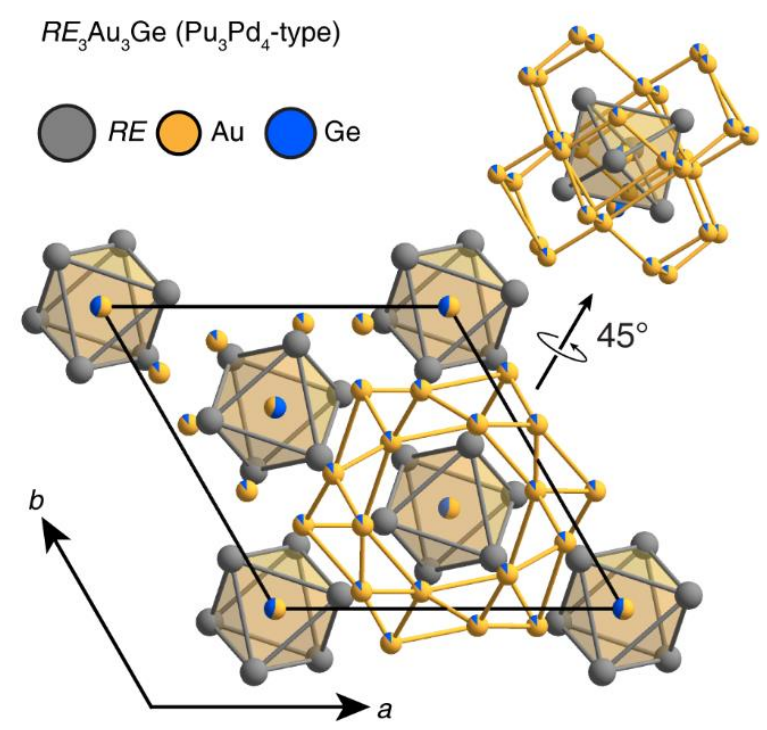

Figure 3. The structure of $\mathrm{Pu}_{3} \mathrm{Pd}_{4}$-type $\mathrm{La}_{3} \mathrm{Au}_{3} \mathrm{Ge}$, highlighting the CsCl-like $\mathrm{La} 8(\mathrm{Au} / \mathrm{Ge})_{33}$ cluster.

The final and most complex series of compounds discovered crystallize in the $\mathrm{Pu}_{3} \mathrm{Pd}_{4}$ structure type with the generic formula $R E_{3} \mathrm{Au}_{3} \mathrm{Ge}(R E=\mathrm{La}, \mathrm{Ce}, \mathrm{Pr}, \mathrm{Nd})$. The $\mathrm{Pu}_{3} \mathrm{Pd}_{4}$ structure type is present in the Inorganic Crystal Structure Database (ICSD) for $R E$-Au binary systems, ${ }^{45}, 46$ including $\mathrm{Nd}_{3} \mathrm{Au}_{4}$ and $\mathrm{Th}_{3} \mathrm{Au}_{4}{ }^{47-49}$ However, it has only once been reported in a ternary system in the form of $\mathrm{Nd}_{3} \mathrm{Pd}_{3.79} \mathrm{Ru}_{0.21}{ }^{50}$ Figure 3 shows the large rhombohedral unit cell of this structure type solved from single-crystal diffraction data for $\mathrm{La}_{3} \mathrm{Au}_{3} \mathrm{Ge}$ (crystallographic data provided in Tables 2-4), and the refined cell parameters are provided for the $R E_{3} \mathrm{Au}_{3} \mathrm{Ge}$ family prepared here in Table 1 . The solved $\mathrm{La}_{3} \mathrm{Au}_{3} \mathrm{Ge}$ structure is characterized by an $\mathrm{AlB}_{2}$-like arrangement of $R E$ octahedra centered by a disordered mixture of $\mathrm{Au}(43 \%)$ and Ge (57\%). Forming a scaffolding layer between the octahedra is an Au-rich (89\%) network of atoms forming hexagonal channels that run along the $c$-axis of the structure. This leads to an overall refined composition of $\mathrm{La}_{3} \mathrm{Au}_{3.17(1)} \mathrm{Ge}_{0.83(1)}$ for this structure. Contact 
distances between $\mathrm{Au}$ atoms in this network range from $2.8 \AA$ to $3.5 \AA$, within standard ranges of aurophilic contacts. ${ }^{51,52}$ Interestingly, through a roughly $45^{\circ}$ rotation, the scaffolding lattice and octahedral $\mathrm{La}_{8}(\mathrm{Au} / \mathrm{Ge})_{33}$ unit can be viewed together as a highly distorted CsCl-like fragment, in which cubes of $\mathrm{Au}$ and Ge house the $R E$ atoms. The intergrowth of this cubic motif with octahedral units suggests that primarily polar interactions between the Au-rich structural units and $R E$ domains stabilize the structural building blocks. These interfaces between the metallically delocalized electrons in the $\mathrm{Au}$ bonding network and Au-centered $R E$ polyhedra also hint at some intriguing structural chemistry that can be investigated through DFT electronic structure calculations.

Electronic Structure Investigation with DFT. The electronic stability of polar intermetallic compounds is understood to be controlled by a complicated mixture of structurally-related effects. Differing interpretations of the interatomic interactions in polar intermetallic compounds lead to disparate frameworks for understanding these structure-properties relationships. A classical Hume-Rothery approach would connect stability to valence electron count and Fermi surface-Brillouin zone interactions,53 whereas looking through the Zintl lens, charge transfer and filled octets are paramount. ${ }^{44}$ To parse the relative contributions of these effects in highly-polar Au-containing $R E-$ $\mathrm{Au}-T t$ phases, density functional theory (DFT) calculations can be employed to investigate the electronic structure of these newly reported compounds directly. 

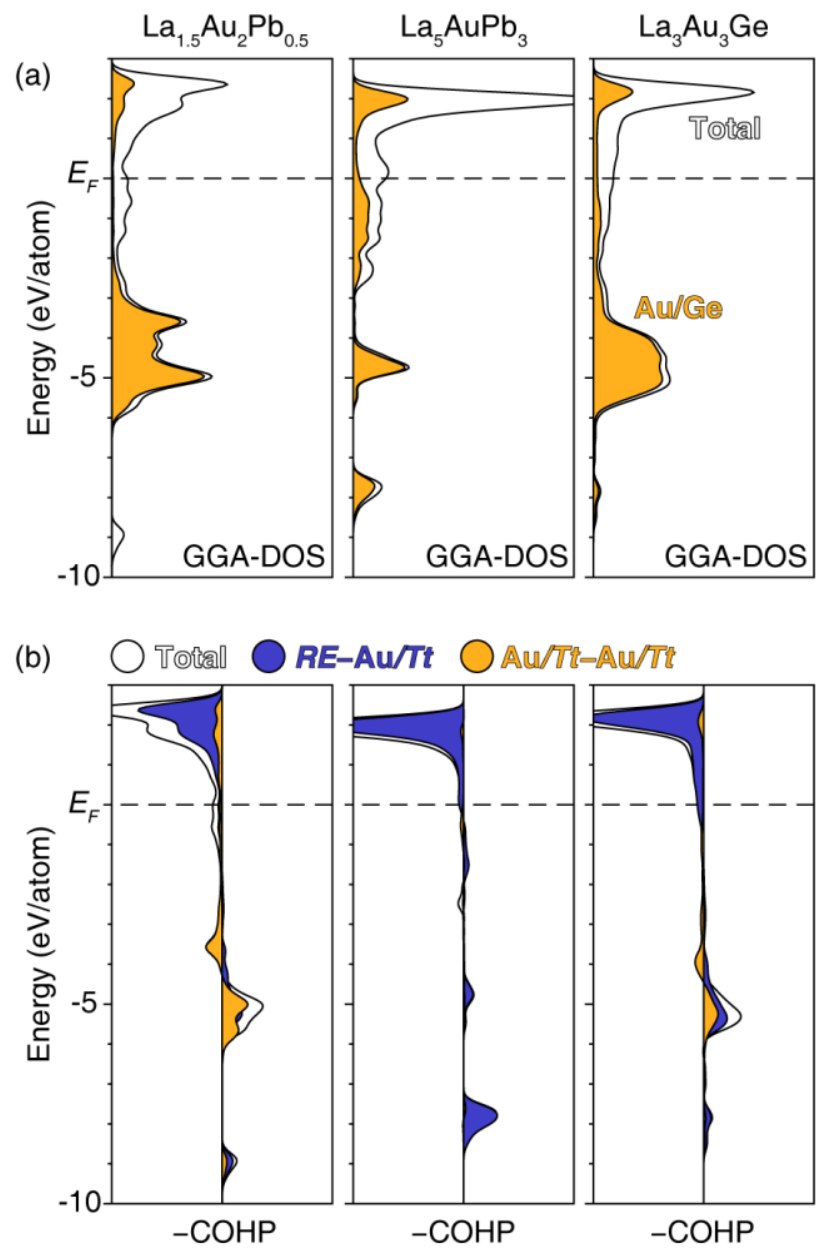

Figure 4. Electronic structure calculations on $\mathrm{La}_{1.5} \mathrm{Au}_{2} \mathrm{~Pb}_{0.5}, \mathrm{La}_{5} \mathrm{AuPb}_{3}$, and $\mathrm{La}_{3} \mathrm{Au}_{3} \mathrm{Ge}$ show (a) density of states (DOS) and, (b) crystal orbital Hamilton population (-COHP) curves showing the total (black), $R E-\mathrm{Au} / \mathrm{Tt}$ (blue), and $\mathrm{Au} / \mathrm{Tt}-\mathrm{Au} / \mathrm{Tt}$ (gold) interactions.

Interactions between the Fermi surface and Brillouin zone can lead to structural stability in intermetallics via the electronic structure. ${ }^{55}$ One way to visualize this is with a density of states (DOS) plot, such as those shown for $\mathrm{La}_{1.5} \mathrm{Au}_{2} \mathrm{~Pb}_{0.5}, \mathrm{La}_{5} \mathrm{AuPb}_{3}$, and $\mathrm{La}_{3} \mathrm{Au}_{3} \mathrm{Ge}$ in Figure $4 \mathrm{a}$. The band population for each structure is plotted against energy, with $E_{F}$ marking the level below which bands are filled with electrons. In this picture, a peak in the DOS shows a high population of bands at a particular energy value, whereas a local minimum, or pseudogap, in the DOS represents an energy level with relatively few bands. For electronically stable systems, Fermi surface-Brillouin zone interactions open up pseudogaps in the DOS at $E_{F}$, which lowers the energies of the highest occupied crystal 
orbitals. Therefore, DOS plots that show the presence of a pseudogap at the Fermi level are correlated with energetically favorable phases, whereas $E_{F}$ falling on a DOS peak is associated with electronic instability. However, the picture is much simpler for the three structures investigated here. The DOS plot near $E_{F}$ is nearly flat for each compound, indicating few, if any, stabilizing effects coming from atomic orbital overlap in these crystal structures. This is further confirmed by investigating the crystal orbital Hamilton population (-COHP) curves. These calculations show the contributions to bonding (positive when plotted as negative COHP) and antibonding (negative when plotted as negative COHP) interactions plotted against energy. In the COHP curve shown for each structure in Figure $4 \mathrm{~b}$, the total COHP and specific $R E-\mathrm{Au} / T t$ and $\mathrm{Au} / T t-\mathrm{Au} / \mathrm{Tt}$ interactions show that very few bonding or antibonding interactions occur near the Fermi level. Thus, the DOS and COHP indicate that these structures are likely not stabilized primarily through orbital overlap.

a) $\mathrm{La}_{1.5} \mathrm{Au}_{2} \mathrm{~Pb}_{0.5}$

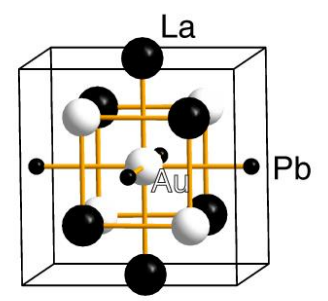

b) $\mathrm{La}_{5} \mathrm{AuPb}_{3}$

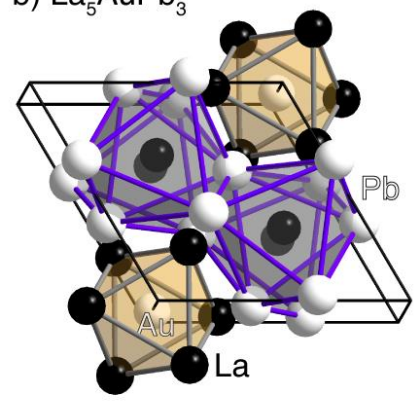

c) $\mathrm{La}_{3} \mathrm{Au}_{3} \mathrm{Ge}$

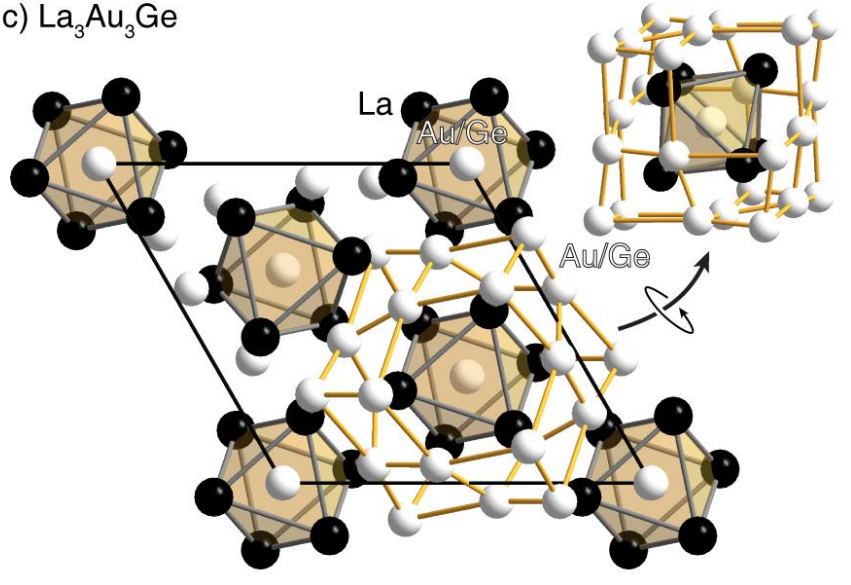


Figure 5. Bader ionicity calculations for a) $\mathrm{La}_{1.5} \mathrm{Au}_{2} \mathrm{~Pb}_{0.5}$, b) $\mathrm{La}_{5} \mathrm{AuPb}_{3}$, and c) $\mathrm{La}_{3} \mathrm{Au}_{3} \mathrm{Ge}$. In this scheme, white spheres represent anionic atoms, and black spheres represent cations. The volume of each sphere is proportional to the magnitude of the charge.

Next, investigating the role of electrostatic interactions shows that significant differences in electronegativity (EN) between $R E$ elements and $\mathrm{Au}\left(\mathrm{EN}_{\mathrm{La}}=1.10, \mathrm{EN}_{\mathrm{Au}}=2.54\right)$ provide a moderate charge transfer. Consequently, electrostatic interactions may have a significant role in the stability of the compounds reported here. To quantitatively assess this charge transfer, DFT-calculated Bader charges were determined for each atom in the La-containing structures. Bader charges are tabulated by assigning the DFT-calculated electron density within a structure to each atom according to the Bader method, which divides space at the zero flux surface of the electron density between atoms. ${ }^{37}$ The result of this calculation for each structure is plotted in Figure 5, where black and white spheres represent cationic and anionic atoms, respectively, and the volume of each sphere is proportional to the tabulated Bader charge (calculated Bader charges given in Table S5). Examining these Bader schemes for each La-containing structure shows that $R E$ atoms are cationic and Au atoms are anionic, as would be expected from their respective electronegativities. In $\mathrm{La}_{1.5} \mathrm{Au}_{2} \mathrm{~Pb}_{0.5}$, the cubic $\mathrm{Au}$ coordination environment contains half $\mathrm{Au}$ contacts and half $\mathrm{La} / \mathrm{Pb}$ disordered sites. The ability of $\mathrm{La}$ and $\mathrm{Pb}$ to occupy the same position in this structure is clarified with the observation that both atoms behave as cations relative to the highly electronegative $\mathrm{Au}$ atoms, even though $\mathrm{Pb}$ is only slightly less electronegative $\left(\mathrm{EN}_{\mathrm{Pb}}=2.33\right)$. Nevertheless, $\mathrm{Pb}$ adopts cationic character maximizing these favorable secondary electrostatic interactions. Intriguingly, the $\mathrm{La}_{1.5} \mathrm{Au}_{2} \mathrm{~Pb}_{0.5}$ phase chooses to adopt the NaTl-type instead of the full Heusler structure, which would seem to be better optimized for maximizing favorable electrostatic interactions. This suggests that the shorter $\mathrm{Au}-\mathrm{Au}$ contacts of the NaTl-type are crucial to the structure preference and that electrostatic effects do not purely govern this compound

Despite containing the same combination of elements, the ionicity of $\mathrm{Pb}$ is inverted in the $\mathrm{La}_{5} \mathrm{AuPb}_{3}$ structure. In this phase, anionically-centered Au@La6 octahedra are intergrown with 
ionically opposite La@Pb6 6 clusters. This arrangement of charges increases the favorable interactions between positive and negative ions within and between adjacent clusters. Considering Pb's behaves like a cation in $\mathrm{La}_{1.5} \mathrm{Au}_{2} \mathrm{~Pb}_{0.5}$, these results suggest that $\mathrm{Pb}$ can behave amphionically in this compositional space, filling whatever ionic role is needed to suit the more extreme electronegativities of La and Au.

The $\mathrm{La}_{3} \mathrm{Au}_{3} \mathrm{Ge}$ structure contains the same Au@La $\mathrm{L}_{6}$ octahedra as those seen in $\mathrm{La}_{5} \mathrm{AuPb}_{3}$. However, without an oppositely charged cluster to satisfy this arrangement, the outlying cationic La atoms are instead buffered by the scaffolding network of Au atoms. The atoms in this layer form distorted cubes around each La, housing each cation within an Au-rich coordination environment. A Bader analysis shows that each structure is arranged to create significantly favorable electrostatic interactions, especially between $R E$ and $\mathrm{Au}$ atoms as seen in the octahedral clusters in $\mathrm{La}_{5} \mathrm{AuPb}_{3}$ and $\mathrm{La}_{3} \mathrm{Au}_{3} \mathrm{Ge}$. This aligns with expectations given the electronegativities of these elements. However, other aspects of these phases, such as nearest-neighbor $\mathrm{Au}-\mathrm{Au}$ contacts in $\mathrm{La}_{1.5} \mathrm{Au}_{2} \mathrm{~Pb}_{0.5}$ and $\mathrm{La}_{3} \mathrm{Au}_{3} \mathrm{Ge}$, seem to run counter to a purely electrostatically-driven structural model. This discrepancy implies that other factors contribute to the stability of these compounds, such as potential delocalized metallic bonding.

The final potential source of stability in these compounds stems from delocalized metallic bonding. Electron localization function (ELF) calculations are beneficial for identifying delocalized electrons within an intermetallic structure. ${ }^{56}$ Figure 6 shows the structures of $\mathrm{La}_{1.5} \mathrm{Au}_{2} \mathrm{~Pb}_{0.5}, \mathrm{La}_{5} \mathrm{AuPb}_{3}$, and $\mathrm{La}_{3} \mathrm{Au}_{3} \mathrm{Ge}$ overlaid with slices of the calculated ELF surface. In these plots, values close to zero (deep blue) represent locations in the electronic structure with a very low probability of locating electrons, such as in the space between atoms. Values close to 1 (red), on the other hand, show locations of highly localized electrons, such as in core states, covalent bonds, or lone pairs. In between, ELF values of 0.5 correspond to fully delocalized electrons, such as those in an electron gas. The ELF plots for these structures all show a combination of these features. In the $\mathrm{La}_{1.5} \mathrm{Au}_{2} \mathrm{~Pb}_{0.5}$ phase, 
delocalized bonding between $\mathrm{Au}$ atoms is readily apparent along the $\left(\begin{array}{lll}1 & 0 & 1\end{array}\right)$ lattice plane, while the $\left(\begin{array}{lll}0 & 0 & 1\end{array}\right)$ layer shows similar metallic character between $\mathrm{Au}$ and $\mathrm{Pb}$. This delocalized bonding network, especially along the $\mathrm{Au}-\mathrm{Au}$ contacts, hints at the favorability of the NaTl-type structure, which blends electrostatic interactions with metallic $\mathrm{Au}-\mathrm{Au}$ bonding. $\mathrm{La}$ atoms in $\mathrm{La}_{1.5} \mathrm{Au}_{2} \mathrm{~Pb}_{0.5}$ remain noninteracting, as seen in the ELF plot, with regions of deep blue ELF minima separating their electron density from their neighbors. A similar picture is seen for $\mathrm{La}_{5} \mathrm{AuPb}_{3}$ and $\mathrm{La}_{3} \mathrm{Au}_{3} \mathrm{Ge}$, where the $\mathrm{La}$ atoms are also highly localized, and there is significant delocalization and interaction between $\mathrm{Au}$ and the $\mathrm{Pb}$ or $\mathrm{Au} / \mathrm{Ge}$ scaffolding atoms in both structures. Thus, this supports our overall picture of these phases as polar intermetallics, containing a mixture of electrostatically driven interactions, such as those between $R E$ and $\mathrm{Au}$ atoms, and delocalized metallic bonding, such as in the $\mathrm{Au}-\mathrm{Au}$ and $\mathrm{Au}-\mathrm{Tt}$ in all structures.
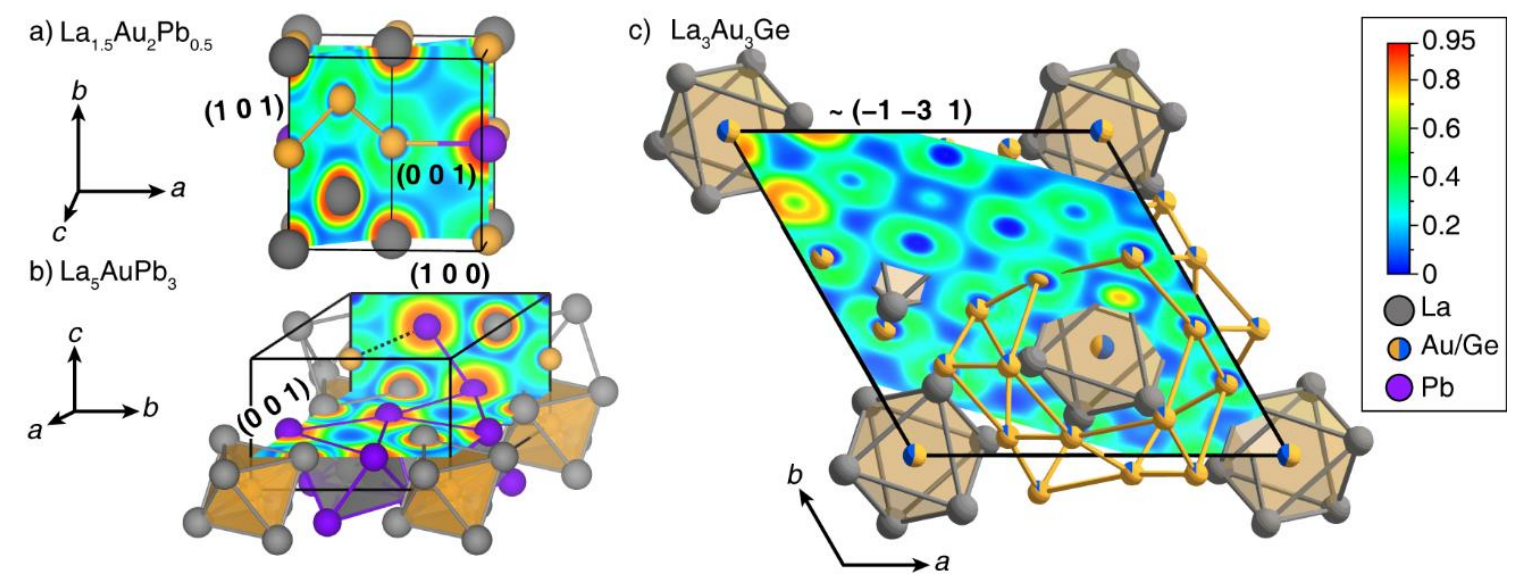

Figure 6. Electron localization function (ELF) slices through a) the $\left(\begin{array}{lll}1 & 0 & 1\end{array}\right)$ and $\left(\begin{array}{lll}0 & 0 & 1\end{array}\right)$ planes in $\left.\mathrm{La}_{1.5} \mathrm{Au}_{2} \mathrm{~Pb}_{0.5}, \mathrm{~b}\right)$ the $\left(\begin{array}{lll}1 & 0 & 0\end{array}\right)$ and $\left(\begin{array}{lll}0 & 0 & 1\end{array}\right)$ planes in $\mathrm{La}_{5} \mathrm{AuPb}_{3}$, and $\left.\mathrm{c}\right)$ the $\sim\left(\begin{array}{lll}-1 & -3 & 1\end{array}\right)$ plane in $\mathrm{La}_{3} \mathrm{Au}_{3} \mathrm{Ge}$.

Altogether, an analysis of the electronic structure in these phases gives us a complete picture of the bonding interactions contributing to their stability. Au-containing polar intermetallics offer a step into a region of solid-state composition space where structures are not controlled by either Fermi Surface-Brillouin Zone interactions or by the filling of octets through complete charge transfer. The characteristic mixture of delocalized metallic bonding and favorable electrostatic interactions 
potentially presents a unique pathway for forming highly unusual metallic oxidation states and stabilizing structures only accessible through gold's extraordinary electronegativity.

\section{Conclusion}

A synthetic investigation into the underexplored $R E-\mathrm{Au}-T t(R E=\mathrm{La}, \mathrm{Ce}, \mathrm{Pr}, \mathrm{Nd}, \mathrm{Ho} ; \mathrm{Tt}=\mathrm{Ge}$, $\mathrm{Sn}, \mathrm{Pb}$ ) composition space revealed eight novel compounds in three structure types: NaTl-type $\mathrm{La}_{1.5} \mathrm{Au}_{2} \mathrm{~Pb}_{0.5}, \mathrm{Nd}_{2-x} \mathrm{Au}_{2} \mathrm{~Pb}_{x}$, and $\mathrm{Ho}_{2-\mathrm{x}} \mathrm{Au}_{2} \mathrm{Sn}_{x}, \mathrm{Hf}_{5} \mathrm{CuSn}_{3}$-type $\mathrm{La}_{5} \mathrm{AuPb}_{3}$, and $\mathrm{Pu}_{3} \mathrm{Pd}_{4}$-type $R E_{3} \mathrm{Au}_{3} \mathrm{Ge}(R E$ $=\mathrm{La}, \mathrm{Ce}, \mathrm{Pr}, \mathrm{Nd}$ ). Each compound was synthesized through the direct high-temperature reaction of elements and subsequent annealing at $850^{\circ} \mathrm{C}$. These compounds are representative polar intermetallics, which are notable for their complex structural features originating from a combination of electronic, electrostatic, and metallic bonding schemes. Au-containing polar intermetallics are of particular interest due to Au's uniquely high electronegativity among transition metals, which enables the stabilization of ternary structures that are not realizable in other systems. Deconvolution of the bonding contributions in these phases can be determined through a DFT investigation of each compound's electronic structure. The density of states and crystal orbital Hamilton populations reveal approximately optimized bonding interactions without a notable pseudogap at the Fermi level, indicating that Fermi surface-Brillouin zone interactions do not govern stability. Visualizations of the calculated Bader charges in these compounds show that electrostatic forces are a vital stabilizing force in these structures, where Au and $T t$ bonding network maximizes the anionic-cationic interactions. To finally examine the metallic bonding, ELF calculations indicate delocalized electrons in the $\mathrm{Au} / \mathrm{Tt}$ bonding networks while $R E$ atoms remain electronically isolated. $R E-\mathrm{Au}-\mathrm{Tt}$ polar intermetallic compounds present a composition space ripe for exploring novel materials with complex crystalline and magnetic structures.

\section{ASSOCIATED CONTENT}




\section{Supporting Information}

The Supporting Information is available free of charge on the ACS Publications website at DOI: XXXXXX.

Powder X-ray diffraction data, Anisotropic displacement parameters for $\mathrm{La}_{1.5} \mathrm{Au}_{2} \mathrm{~Pb}, \mathrm{La}_{5} \mathrm{AuPb}_{3}$, and $\mathrm{La}_{3} \mathrm{Au}_{3} \mathrm{Ge}$, DFT total energies, DFT optimized geometries, DFT calculated Bader charges.

\section{Accession Codes}

CCDC reference numbers 2129946, 2129947, and 2129948 contain the supplementary crystallographic data for this paper. These data can be obtained free of charge via www.ccdc.cam.ac.uk/data_request/cif, or by emailing data_request@ccdc.cam.ac.uk, or by contacting The Cambridge Crystallographic Data Centre, 12 Union Road, Cambridge CB2 1EZ, UK; fax: $+441223336033$

\section{Author Information}

\section{Corresponding Author}

*E-mail: jbrgoch@uh.edu

Notes

The authors declare no competing financial interest.

\section{Acknowledgements}

The authors would like to thank Prof. Arnold M. Guloy, Dr. Xiqu Wang, and Dr. James D. Korp for their helpful discussions. The authors gratefully acknowledge the generous financial support provided by the Welch Foundation (E-1981) and the Texas Center for Superconductivity at the University of Houston (TcSUH). This research utilized the Maxwell/Opuntia/Sabine cluster(s) operated by the Research Computing Data Core at the University of Houston. 


\section{References}

1. Miller, G. J.; Schmidt, M. W.; Wang, F.; You, T.-S., Quantitative advances in the Zintl-Klemm formalism. Zintl phases 2011, 1-55.

2. Miller, G. J.; Thimmaiah, S.; Smetana, V.; Palasyuk, A.; Lin, Q., Gold's Structural Versatility within Complex Intermetallics: From Hume-Rothery to Zintl and even Quasicrystals. MRS Online Proceedings Library (OPL) 2013, 1517.

3. Pauling, L.; Ewing, F. J., The ratio of valence electrons to atoms in metals and intermetallic compounds. Rev. Mod. Phys. 1948, 20 (1), 112.

4. Meyer, G.; Naumann, D.; Wesemann, L., Inorganic chemistry highlights. John Wiley \& Sons: 2002; Vol. 1.

5. $\quad$ Paufler, P.; Villars, P.; Calvert, L., Pearson's handbook of crystallographic data for intermetallic phases. Wiley Online Library: 1986; Vol. 1-3, p 3258.

6. Smetana, V.; Rhodehouse, M.; Meyer, G.; Mudring, A.-V., Gold polar intermetallics: structural versatility through exclusive bonding motifs. Acc. Chem. Res. 2017, 50 (11), 2633-2641.

7. Lin, Q.; Corbett, J. D., Interpenetrating networks of three-dimensional Penrose tiles in $\mathrm{CaAu}_{3} \mathrm{Ga}$, the structurally simplest cubic approximant of an icosahedral quasicrystal. Inorg. Chem. 2008, 47 (9), 3462-3464.

8. Lotfi, S.; Brgoch, J., Discovering Intermetallics Through Synthesis, Computation, and DataDriven Analysis. Chemistry - A European Journal 2020, 26 (40), 8689-8697.

9. Binnewies, M.; Dolinšek, J.; Failamani, F.; Feuerbacher, M.; Fisk, Z.; Guélou, G.; Guo, Q.; Hedo, M.; Henkie, Z.; Ipser, H., Crystal growth of intermetallics. Walter de Gruyter GmbH \& Co KG: 2018.

10. Venturini, G.; Meot-Meyer, M.; Marêché, J.; Malaman, B.; Roques, B., De nouveaux isotypes de $\mathrm{U}_{2} \mathrm{Co}_{3} \mathrm{Si}_{5}$ ou $\mathrm{Lu}_{2} \mathrm{Co}_{3} \mathrm{Si}_{5}$ dans les systems $\mathrm{RT}-\mathrm{Ge}(\mathrm{R}=$ elements des terres rares; $\mathrm{T}=\mathrm{Ru}, \mathrm{Co}, \mathrm{Rh}$, Ir). Supraconductivite de $\mathrm{Y}_{2} \mathrm{Ir}_{3} \mathrm{Ge}_{5}$. Mater. Res. Bull. 1986, 21 (1), 33-39.

11. Gil, A.; Szytuła, A.; Tomkowicz, Z.; Wojciechowski, K.; Zygmunt, A., Magnetic properties of $\mathrm{RNiSi}_{2}$ and $\mathrm{RNiGe}_{2}$ compounds. J. Magn. Magn. Mater. 1994, 129 (2-3), 271-278.

12. Zhang, Y., Review of the structural, magnetic and magnetocaloric properties in ternary rare earth $\mathrm{RE}_{2} \mathrm{~T}_{2} \mathrm{X}$ type intermetallic compounds. J. Alloys Compd. 2019, 787, 1173-1186.

13. Oliynyk, A. O.; Stoyko, S. S.; Mar, A., Many metals make the cut: Quaternary rare-earth germanides $\mathrm{RE}_{4} \mathrm{M}_{2} \mathrm{InGe} 4$ (M= Fe, Co, Ni, Ru, Rh, Ir) and $\mathrm{RE}_{4} \mathrm{RhInGe}_{4}$ derived from excision of slabs in $\mathrm{RE}_{2} \mathrm{InGe}_{2}$. Inorg. Chem. 2015, 54 (6), 2780-2792.

14. Benkaddour, Y.; Abdelaoui, A.; Yakoubi, A.; Khachai, H.; Al-Douri, Y.; Omran, S. B.; Shankar, A.; Khenata, R.; Voon, C. H.; Prakash, D., First-Principle Calculations of Structural, Elastic, and Electronic Properties of Intermetallic Rare Earth $\mathrm{R}_{2} \mathrm{Ni}_{2} \mathrm{~Pb}(\mathrm{R}=\mathrm{Ho}$, Lu, and $\mathrm{Sm}$ ) Compounds. J. Supercond. Nov. Magn. 2018, 31 (2), 395-403.

15. Weiland, A.; Felder, J. B.; McCandless, G. T.; Chan, J. Y., One Ce, Two Ce, Three Ce, Four? An Intermetallic Homologous Series to Explore: $A_{n+1} B_{n} X_{3 n+1}$. Chem. Mater. 2020, 32 (4), 15751580.

16. Bie, H.; Zelinska, O. Y.; Tkachuk, A. V.; Mar, A., Structures and Physical Properties of RareEarth Chromium Germanides RECrGe 3 (RE= La- Nd, Sm). Chem. Mater. 2007, 19 (18), 46134620.

17. Morozkin, A.; Knotko, A.; Yapaskurt, V.; Yuan, F.; Mozharivskyj, Y.; Pani, M.; Provino, A.; Manfrinetti, P., The Ho-Ni-Ge system: Isothermal section and new rare-earth nickel germanides. J. Solid State Chem. 2015, 225, 193-201.

18. Rieger, W.; Parthé, E., Ternäre Erdalkali-und Seltene Erdmetall-Silicide und-Germanide mit $\mathrm{ThCr}_{2} \mathrm{Si}_{2}$-Struktur. Monatsh. Chem. 1969, 100 (2), 444-454. 
19. Szytuła, A.; Kaczorowski, D.; Arulraj, A.; Baran, S.; Penc, B., Magnetic properties of $\mathrm{NdAu}_{2} \mathrm{Ge}_{2}$. J. Magn. Magn. Mater. 2009, 321 (20), 3402-3405.

20. Rossi, D.; Marazza, R.; Ferro, R., Ternary rare earth alloys: RAuGe compounds. J. Alloys Compd. 1992, 187 (2), 267-270.

21. Schnelle, W.; Pöttgen, R.; Kremer, R.; Gmelin, E.; Jepsen, O., The crystal structure, magnetic susceptibility, electrical resistivity, specific heat, and electronic band structure of RAuGe (R= Sc, Y, La, Lu). J. Phys.: Condens. Matter 1997, 9 (7), 1435.

22. Pöttgen, R.; Borrmann, H.; Kremer, R. K., Ferromagnetic ordering in CeAuGe. J. Magn. Magn. Mater. 1996, 152 (1-2), 196-200.

23. Krimmel, A.; Hemberger, J.; Kegler, C.; Nicklas, M.; Engelmayer, A.; Knebel, G.; Fritsch, V.; Reehuis, M.; Brando, M.; Loidl, A., The evolution from long-range magnetic order to spin-glass behaviour in $\operatorname{PrAu}_{2}\left(\mathrm{Si}_{1-\mathrm{x}} \mathrm{Ge}_{\mathrm{x}}\right)_{2}$. J. Phys.: Condens. Matter 1999, 11 (36), 6991.

24. Joshi, D. A.; Nigam, A.; Dhar, S.; Thamizhavel, A., Magnetocrystalline anisotropy in $\mathrm{RAu}_{2} \mathrm{Ge}_{2}$ (R= La, Ce and Pr) single crystals. J. Magn. Magn. Mater. 2010, 322 (21), 3363-3371.

25. Fickenscher, T.; Rodewald, U. C.; Niehaus, O.; Gerke, B.; Haverkamp, S.; Eckert, H.; Poettgen, R., The Stannides $\mathrm{RE}_{3} \mathrm{Au}_{6} \mathrm{Sn}_{5}(\mathrm{RE}=\mathrm{La}, \mathrm{Ce}, \mathrm{Pr}, \mathrm{Nd}, \mathrm{Sm})-$ Synthesis, Structure, Magnetic Properties and ${ }^{119}$ Sn Mössbauer Spectroscopy. Z. Naturforsch. B 2015, 70 (6), 425-434.

26. Toby, B. H., EXPGUI, a graphical user interface for GSAS. J. Appl. Crystallogr. 2001, 34 (2), 210213.

27. Larson, A.; Von Dreele, R., Report LAUR 86-748. Los Alamos National Laboratory, New Mexico, USA 2000.

28. Momma, K.; Izumi, F., VESTA 3 for three-dimensional visualization of crystal, volumetric and morphology data. J. Appl. Crystallogr. 2011, 44 (6), 1272-1276.

29. Impact, C., DIAMOND-Crystal and Molecular Structure Visualization. 2009.

30. Hübschle, C. B.; Sheldrick, G. M.; Dittrich, B., ShelXle: a Qt graphical user interface for SHELXL. J. Appl. Crystallogr. 2011, 44 (6), 1281-1284.

31. Kresse, G.; Furthmüller, J., Efficient iterative schemes for ab initio total-energy calculations using a plane-wave basis set. Phys. Rev. B 1996, 54 (16), 11169.

32. Kresse, G.; Joubert, D., From ultrasoft pseudopotentials to the projector augmented-wave method. Phys. Rev. B 1999, 59 (3), 1758.

33. Blöchl, P. E., Projector augmented-wave method. Phys. Rev. B 1994, 50 (24), 17953.

34. Perdew, J. P.; Burke, K.; Ernzerhof, M., Generalized gradient approximation made simple. Phys. Rev. Lett. 1996, 77 (18), 3865.

35. Deringer, V. L.; Tchougréeff, A. L.; Dronskowski, R., Crystal orbital Hamilton population (COHP) analysis as projected from plane-wave basis sets. J. Phys. Chem. A 2011, 115 (21), 5461-5466.

36. Dronskowski, R.; Bloechl, P. E., Crystal orbital Hamilton populations (COHP): energy-resolved visualization of chemical bonding in solids based on density-functional calculations. J. Phys. Chem. 1993, 97 (33), 8617-8624.

37. Sanville, E.; Kenny, S. D.; Smith, R.; Henkelman, G., Improved grid-based algorithm for Bader charge allocation. J. Comput. Chem. 2007, 28 (5), 899-908.

38. Bader, R. F., Atoms in molecules. Acc. Chem. Res. 1985, 18 (1), 9-15.

39. Henkelman, G.; Arnaldsson, A.; Jónsson, H., A fast and robust algorithm for Bader decomposition of charge density. Comput. Mater. Sci. 2006, 36 (3), 354-360.

40. Pauly, H.; Weiss, A.; Witte, H., Phasenbreite und Valenzelektronenkonzentration (VEK) in den ternären kubischen Zintlphasen vom NaTl-Typ. Int. J. Mater. Res. 1968, 59 (7), 554-558.

41. Krypiakewytsch, P.; Evdokimenko, V., Neue Verbindungen im System DysprosiumMagnesium und in verwandten Systemen. Z. Anorg. Allg. Chem. 1967, 355 (1-2), 104-112.

42. Iandelli, A., Intermetallic compounds of the rare earth metals. Physical Chemistry of Metallic Solutions and Intermetallic Compounds 1959. 
43. Rieger, W.; Nowotny, H.; Benesovsky, F., Phasen mit oktaedrischen Bauelementen des Übergangsmetalls. Monatsh. Chem. Verw. Teile Anderer Wiss. 1965, 96 (1), 232-241.

44. Aronsson, B., An Investigation of the $\mathrm{Me}_{3} \mathrm{Si}_{3}-\mathrm{MeSi}$ Region of the Mn-Fe-Si and Some Related Systems. Acta Chem. Scand. 1958, 12 (2), 11.

45. Fluck, E., Inorganic crystal structure database (ICSD) and standardized data and crystal chemical characterization of inorganic structure types (TYPIX)-Two tools for inorganic chemists and crystallographers. J. Res. Natl. Inst. 1996, 101 (3), 217.

46. Cromer, D.; Larson, A.; Roof, R., The crystal structure of $\mathrm{Pu}_{3} \mathrm{Pd}_{4}$. Acta Crystallogr. Sect. B: Struct. Sci. 1973, 29 (3), 564-567.

47. Fornasini, M.; Saccone, A., Crystal structure of $\mathrm{Nd}_{3} \mathrm{Au}_{4}$ and $\mathrm{Nd}_{17} \mathrm{Au}_{36}$. Z. Kristallogr. Cryst. Mater. 1994, 209 (8), 657-659.

48. Palenzona, A.; Cirafici, S., The Th-Au phase diagram.J. Less Common Met. 1986, 124 (1-2), 245249.

49. Palenzona, A., The crystal structure and lattice constants of $\mathrm{R}_{3} \mathrm{Pt}_{4}$ compounds. J. Less Common Met. 1977, 53 (1), 133-136.

50. Raevskaya, M.; Avertseva, I.; Rusnyak, Y., Interaction of palladium with ruthenium and neodymium[[Previously Titled: Diagram of state of the Pd-Ru-Nd system.]]. Russ. Metall. 1994, 2, 131-135.

51. Seibel, E. M.; Schoop, L. M.; Xie, W.; Gibson, Q. D.; Webb, J. B.; Fuccillo, M. K.; Krizan, J. W.; Cava, R. J., Gold-Gold Bonding: The Key to Stabilizing the 19-Electron Ternary Phases Ln AuSb (Ln= La-Nd and Sm). J. Am. Chem. Soc. 2015, 137 (3), 1282-1289.

52. Schmidbaur, H.; Schier, A., A briefing on aurophilicity. Chem. Soc. Rev. 2008, 37 (9), 19311951.

53. Mizutani, U., The Hume-Rothery rules for structurally complex alloy phases. In Surface Properties and Engineering of Complex Intermetallics, World Scientific: 2010; pp 323-399.

54. Nordell, K. J.; Miller, G. J., Linking intermetallics and zintl compounds: An investigation of ternary trielides (Al, Ga, In) forming the $\mathrm{NaZn}_{13}$ structure type. Inorg. Chem. 1999, 38 (3), 579-590.

55. Mizutani, U.; Kondo, Y.; Nishino, Y.; Inukai, M.; Feuerbacher, M.; Sato, H., Fermi surfaceBrillouin-zone-induced pseudogap in $\gamma-\mathrm{Mg}_{17} \mathrm{Al}_{12}$ and a possible stabilization mechanism of $\beta$ $\mathrm{Al}_{3} \mathrm{Mg}_{2}$. J. Phys.: Condens. Matter 2010, 22 (48), 485501.

56. Silvi, B.; Savin, A., Classification of chemical bonds based on topological analysis of electron localization functions. Nature 1994, 371 (6499), 683-686. 
Table of Contents

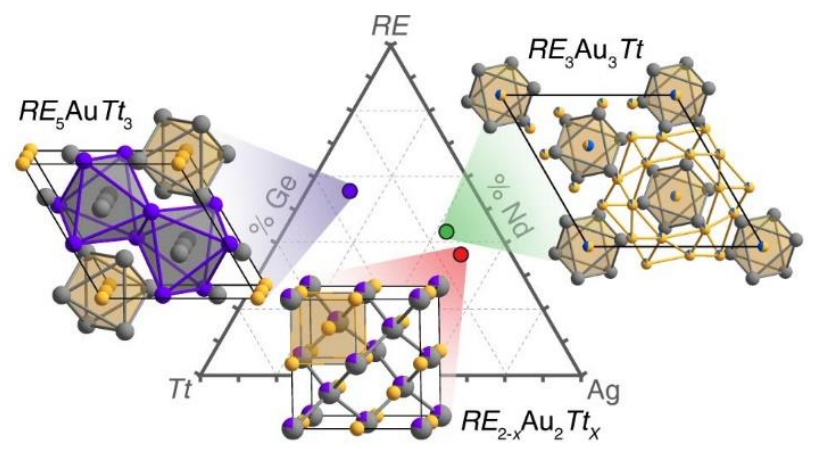

